\title{
Corals and Their Potential Applications to Integrative Medicine
}

\author{
Edwin L. Cooper, ${ }^{1}$ Kyle Hirabayashi, ${ }^{1}$ Kevin B. Strychar, ${ }^{2}$ and Paul W. Sammarco ${ }^{3}$ \\ ${ }^{1}$ Laboratory of Comparative Neuroimmunology, Department of Neurobiology, David Geffen School of Medicine at UCLA, \\ Los Angeles, CA 90095-1763, USA \\ ${ }^{2}$ Annis Water Resources Institute, Grand Valley State University, Muskegon, MI 49441-1678, USA \\ ${ }^{3}$ Louisiana Universities Marine Consortium (LUMCON), 8124 Highway 56, Chauvin, LA 70344-2110, USA
}

Correspondence should be addressed to Edwin L. Cooper; ecam@mednet.ucla.edu

Received 5 November 2013; Accepted 23 December 2013; Published 13 March 2014

Academic Editor: Tung-Sheng Chen

Copyright (c) 2014 Edwin L. Cooper et al. This is an open access article distributed under the Creative Commons Attribution License, which permits unrestricted use, distribution, and reproduction in any medium, provided the original work is properly cited.

\begin{abstract}
Over the last few years, we have pursued the use and exploitation of invertebrate immune systems, most notably their humoral products, to determine what effects their complex molecules might exert on humans, specifically their potential for therapeutic applications. This endeavor, called "bioprospecting," is an emerging necessity for biomedical research. In order to treat the currently "untreatable," or to discover more efficient treatment modalities, all options and potential sources must be exhausted so that we can provide the best care to patients, that is, proceed from forest and ocean ecosystems through the laboratory to the bedside. Here, we review current research findings that have yielded therapeutic benefits, particularly as derived from soft and hard corals. Several applications have already been demonstrated, including anti-inflammatory properties, anticancer properties, bone repair, and neurological benefits.
\end{abstract}

\section{What Are Corals?}

Corals have served as an excellent target taxon for bioprospecting [1-4]. The earth's surface is covered by $\sim 70 \%$ water and contains $80 \%$ of all life found on the planet [5]. It is no wonder then that the ocean has been and still is a source of food, let alone a vast source of therapeutic molecules. In our case, corals will be the subject of our investigation. Corals (Phylum: Cnidaria, Class: Anthozoa) can generally be categorized into hard, soft, or gorgoniantype organisms. Hard corals, called Scleractinian corals, are generally hermatypic, the types that build reefs, with which most people are familiar. Soft corals or octocorals are generally flexible and do not produce the rigid structure characteristic of hard corals [6]. Gorgonian corals are also flexible, but their skeletal systems consist of a horny substance called gorgonin. Some of these coral types contain symbiotic microalgae, genus Symbiodinium, and are generally called zooxanthellae [7]. These coral types tend to reside in shallow waters of tropical and subtropical locales.
Through the extensive work of Metchnikoff, we now know of cellular and humoral immunity as well as the importance of invertebrate organisms in immunologic research $[8$, 9]. The revelation of a division between innate and adaptive immunity came much later. The innate immune system is natural, nonspecific, nonanticipatory, nonclonal, germ line, and for which there is no evidence that such a system possesses the capacity to build memory from past exposures. Conversely, the adaptive immune system is acquired, specific, anticipatory, clonal, and somatic and possesses the capacity to build memory from past exposures [10]. Adaptive or acquired immunity has always been associated with vertebrates while the innate immune system is generally thought to have originated in the invertebrates [11]. We propose immune-related products as sources of therapeutic molecules (Figure 1).

The discipline of coral immunology has not been vastly studied and is not completely understood. While many mechanisms associated with other organisms have been identified and examined, the general system of coral immunology still requires further investigation [12]. One of the mechanisms 


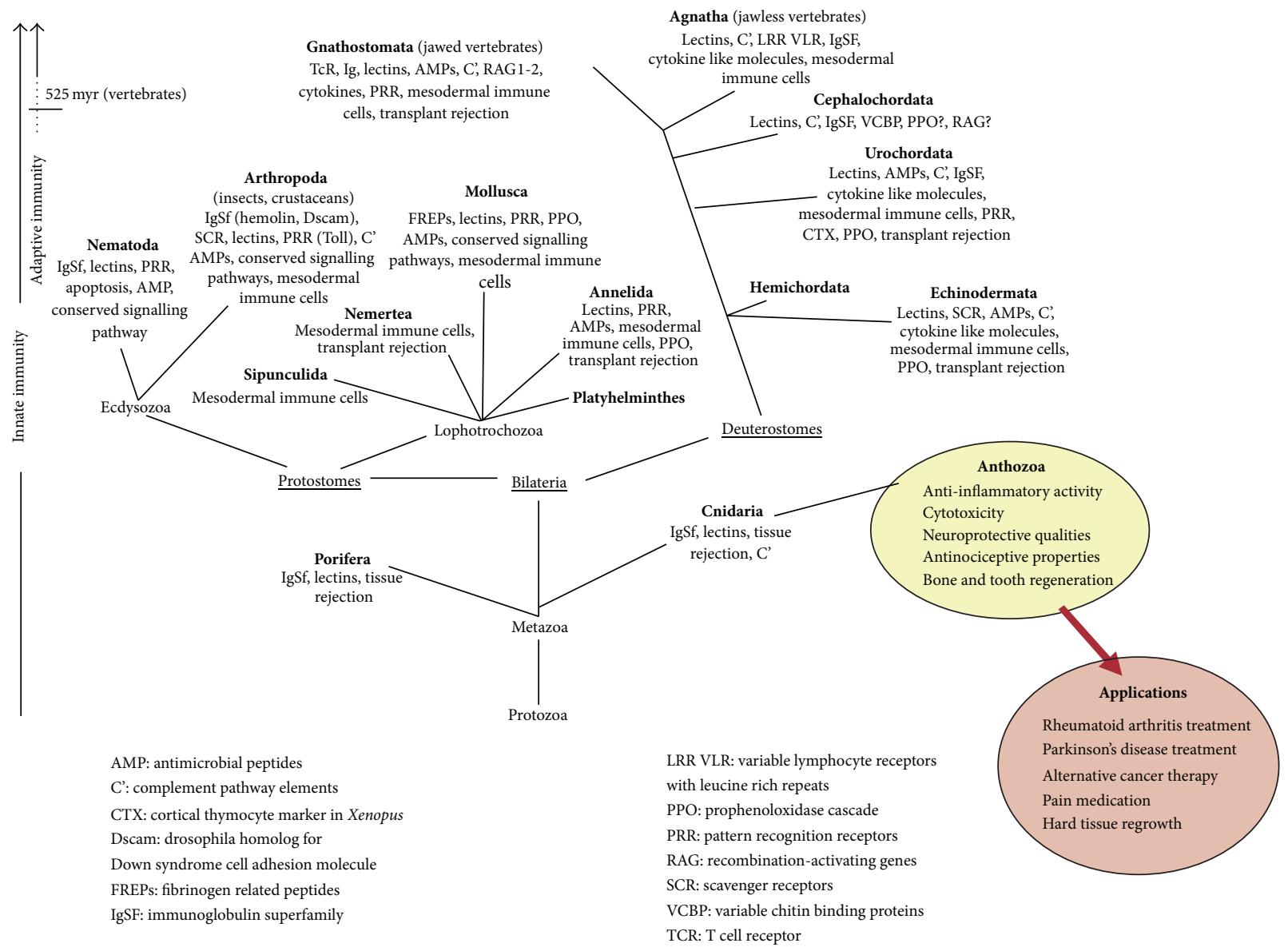

FIgURE 1: An evolutionary map indicating where corals (Anthozoa) lie and some of the therapeutic benefits they exert. Adapted from [11].

that has been demonstrated extensively is alloimmune memory, or reaction to and rejection of cells and molecules from members of the same species. For example, Montipora verrucosa, a hard (Scleractinian) coral, actually displays a limited form of memory during analyses of transplantation responses $[13,14]$. Alloimmune memory in this coral seems to be due to varying histocompatibility markers that serve as identification badges of self/nonself. We will now turn to the therapeutic benefits of certain coral species.

\section{Corals and Inflammation}

Perhaps disorders most related to the immune system are those of inflammation. Inflammation is a physiological protective mechanism that is activated by the immune system upon encountering foreign invaders in an attempt to remove the adverse stimuli and begin healing the organism. Diterpenes are one specific class of molecules isolated from corals that have been shown to exhibit therapeutic benefits, specifically anti-inflammatory. Three diterpenes isolated from Eunicea fusca, a gorgonian coral native to Florida, were found to have superior anti-inflammatory effects to those of indomethacin, a commonly used anti-inflammatory medication [15]. Another diterpene isolated from the same species of coral, fucoside E, showed the same anti-inflammatory activity as well as antimicrobial activity [16]. Sinularin, a molecule that we will discuss later in greater detail, blocks pathways that increase the severity of neuroinflammation (see Table 1 for a more extensive list of therapeutic molecules isolated from corals) [17].

One particular clinical application that has proven to be especially promising in relation to coral natural products is arthritis. Rheumatoid arthritis is a chronic inflammatory disease that causes joint destruction. In a recent article published in PLoS, 11-epi-sinulariolide acetate (Ya-s11), a known cembrane-type compound, was isolated from the soft coral, Sinularia querciformis, and evaluated in its anti-inflammatory potency in vitro as well as in adjuvant-induced arthritis (AIA) in rats (Figure 2) [18]. AIA is the typical murine equivalent to human rheumatoid arthritis used in experiments to test treatment possibilities. Ya-s11 was shown to strongly inhibit the production of proinflammatory proteins iNOS and COX-2 in murine macrophages (Figure 3). In the AIA mice, Ya-s11 severely reduced the effects of arthritis by inhibiting migration of inflammatory cells to joints and preventing bone destruction (Figure 4). The authors concluded that this molecule may be a source of treatment for humans with rheumatoid arthritis. To draw a correlation here, there have also been other demonstrations of AIA attenuation in rats 
TABLE 1: Bioactive compounds with medicinal qualities.

\begin{tabular}{|c|c|c|c|c|}
\hline Genus & Species & Molecule & Benefit & Author \\
\hline \multirow[t]{6}{*}{ Sinularia } & flexibilis & $\begin{array}{l}\text { Flexibiliquinone } \\
\text { Flexibilin D }\end{array}$ & Anti-inflammation & $\begin{array}{l}\text { Lin et al. } 2013 \text { [47] } \\
\text { Hu et al. } 2013 \text { [48] }\end{array}$ \\
\hline & querciformis & $\begin{array}{c}\text { 11-epi-Sinulariolide } \\
\text { Acetate } \\
\text { Sinularin }\end{array}$ & $\begin{array}{l}\text { Anti-inflammation and } \\
\text { anti-bone-loss } \\
\text { Antinociception and } \\
\text { antineuroinflammation }\end{array}$ & $\begin{array}{c}\text { Lin et al. } 2013 \text { [18] } \\
\text { Huang et al. } 2012 \text { [17] }\end{array}$ \\
\hline & gaweli & $5 \alpha, 8 \alpha$-Epidioxysterol & Cytotoxicity & Yen et al. 2013 [49] \\
\hline & crassa & Crassalone A & Cytotoxicity & Cheng et al. 2012 [50] \\
\hline & granosa & 9,11-Secosterol & $\begin{array}{l}\text { Cytotoxicity and } \\
\text { anti-inflammation }\end{array}$ & Huang et al. 2012 [51] \\
\hline & sp. & $\begin{array}{l}5 \text {-Epsinuleptolide } \\
\text { acetate (5EPA) }\end{array}$ & Cytotoxicity & Huang et al. 2013 [24] \\
\hline Scleronephthya & gracillimum & Sclerosteroids & $\begin{array}{l}\text { Cytotoxicity and } \\
\text { anti-inflammation }\end{array}$ & Fang et al. 2013 [52] \\
\hline Cladiella & krempfi & Kremptielins & $\begin{array}{l}\text { Cytotoxicity and } \\
\text { anti-inflammation }\end{array}$ & Tai et al. 2013 [53] \\
\hline Paraminabea & acronocephala & Paraminabic acid & $\begin{array}{c}\text { Cytotoxicity and } \\
\text { anti-inflammation }\end{array}$ & Chao et al. 2013 [54] \\
\hline Capnella & imbricata & Capnellenes & $\begin{array}{l}\text { Antineuroinflammation } \\
\text { and antinociception }\end{array}$ & Jean et al. 2009 [37] \\
\hline Lemnalia & cervicomi tenuis & Lemnalol & $\begin{array}{l}\text { Anti-inflammation and } \\
\text { antinociception }\end{array}$ & Lee et al. 2013 [55] \\
\hline Echinomuricea & sp. & Echinoclerodane A & $\begin{array}{l}\text { Cytotoxicity and } \\
\text { anti-inflammation }\end{array}$ & Cheng et al. 2012 [56] \\
\hline Nephthea & chabrolii & $\begin{array}{c}\text { Nebrosteroids Q, R, and } \\
\text { S }\end{array}$ & Cytotoxicity & Wang et al. 2013 [27] \\
\hline
\end{tabular}

through the use of herbal products (Figure 5) [19]. Although the investigators used different methods for evaluating the effectiveness, the point we are making is that there are various potential natural treatments, whether plant or animal, being tested for the treatment of arthritis. Next, we will examine anticancer effects that some coral natural products exert.

\section{Corals and Cancer}

3.1. The Role of Sinularia in Cancer. One particular genus of corals possesses a natural metabolite which has demonstrated significant anticancer ability. They are species of the soft coral genus Sinularia. Goto et al. isolated an agglutinin called sinularian from this species and found that it agglutinated experimental targets, for example, rabbit erythrocytes and murine leukemia cells, but not sheep or human erythrocytes [20]. Incidentally responses to foreign erythrocytes are a common approach used in analyzing the innate immune system of invertebrates. Moreover, Wright et al. isolated various compounds from corals of this genus, including a new nitrogenous diterpene, new and known lobanes, and known cembranes [21]. The lobanes and cembranes were tested for anticancer activity against three human cancer cell lines and showed a $50 \%$ inhibition of tumor growth. Not only does this coral's product exhibit anticancer activity, but it also exerts pronounced anti-inflammatory responses.
The innate immune system's property of phagocytosis gave rise to the well-understood common inflammatory system and its responses. Novel steroids isolated from Sinularia crassa were found to downregulate expression of proinflammatory proteins and showed cytotoxic activity against human liver cancer cells [22]. Another molecule isolated from Sinularia sp., sinularin, demonstrated anticancer activity via proapoptotic factors (Figure 6) [23]. Apoptosis refers to one type of programmed cell death leading to particular cell conformational changes and death. 5-episinuleptolide acetate (5EPA), a norcembranoidal diterpene, isolated from Sinularia sp., has demonstrated cytotoxicity against many cell lines including K562, Molt 4, and HL 60, with HL 60 being the most sensitive to this treatment via Hsp90 inhibition (Figure 7) [24]. Hsp90 inhibition leads to apoptosis or cell death in the leukemia cells.

3.2. Other Species of Soft Corals with Anticancer Properties. Other species, besides those in the genus Sinularia, have also demonstrated anticancer potential. One in particular, 13-acetoxysarcocrassolide, isolated from the soft coral Sarcophyton crassocaule exerted cytotoxic activity against bladder cancer cells [25]. Wang and Duh isolated six novel cembranolides called michaolides and a known cembranolide called lobomichaolide from the soft coral Lobophytum michaelae 


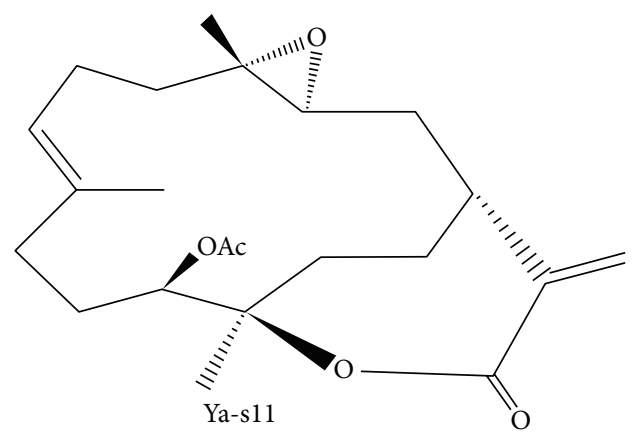

(a)

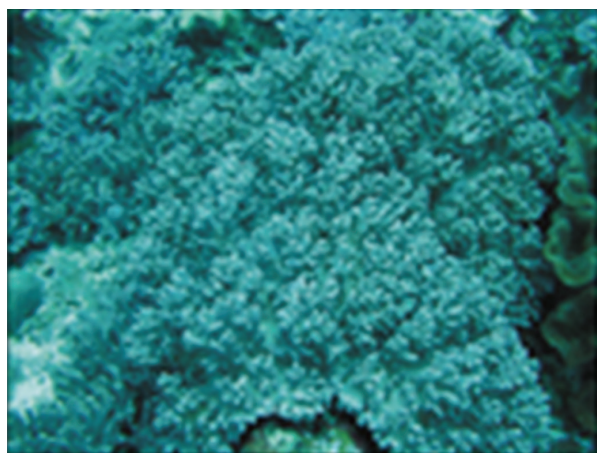

(b)

Figure 2: The chemical structure of 11-epi-sinulariolide acetate (Ya-s11) and the coral from which it is isolated, Sinularia querciformis. From $[18]$.

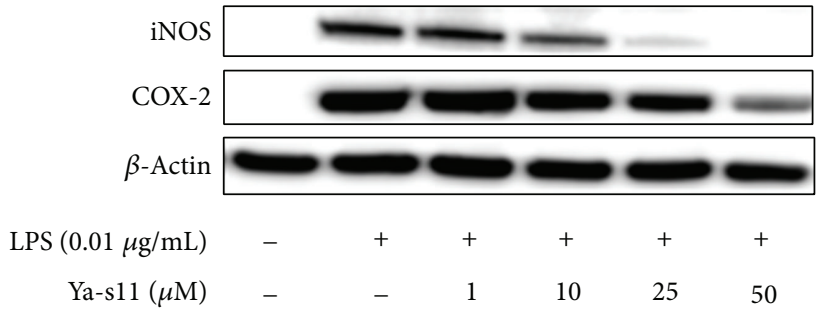

(a)

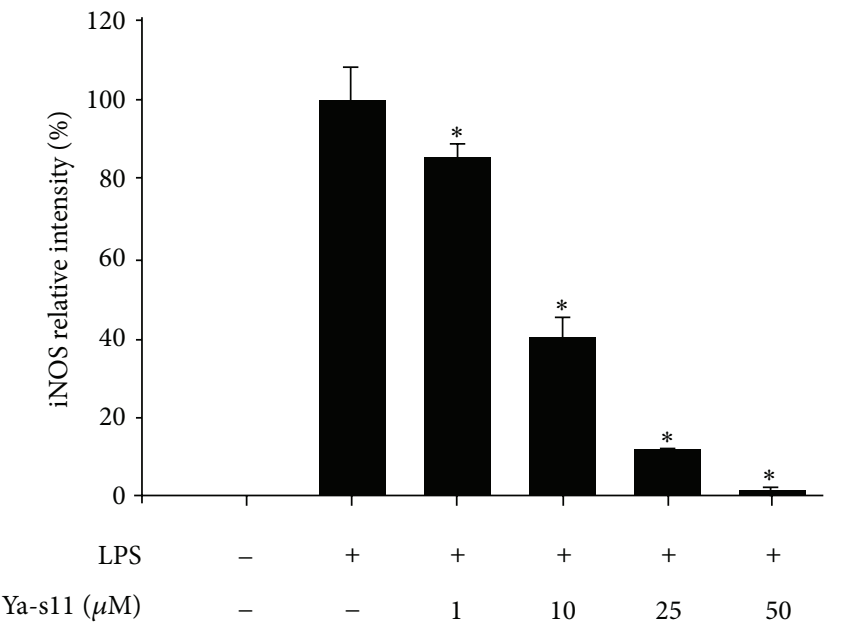

(b)

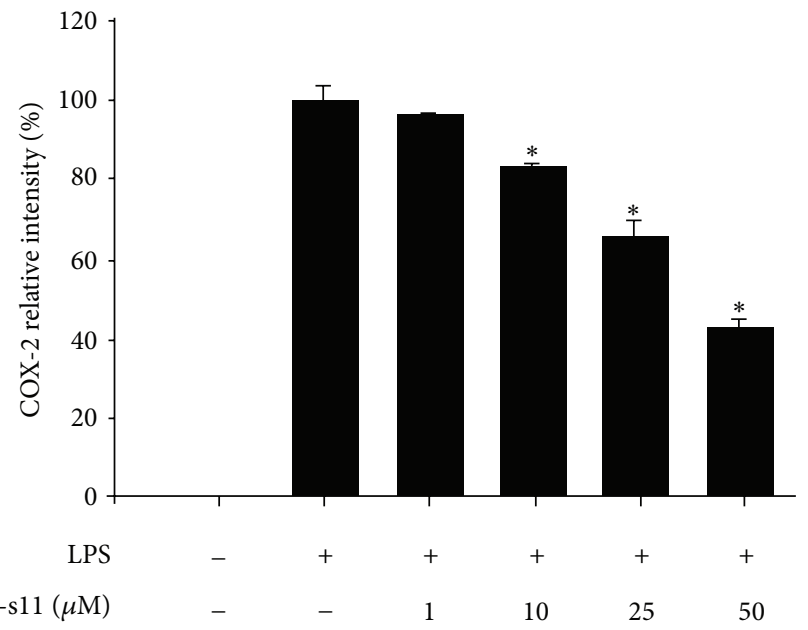

(c)

FIGURE 3: In vitro effects of Ya-s11 on production of iNOS and COX-2, proinflammatory proteins. From [18].

and determined that they possessed not only antitumor capabilities, but also activity against cytomegalovirus (HCMV), related to herpesviruses [26].

Another genus of corals that has proven particularly generous with its demonstrations of marine natural products is Nephthea [27]. Wang, Puu, and Duh isolated three new steroids, nebrosteroids Q, R, and S, from the soft coral Nephthea chabrolii and tested its anticancer and antiviral activity. They found that these three steroids did exhibit cytotoxicity against the P-388 cell line (mouse lymphocytic leukemia) but did not exhibit antiviral activity against HCMV.

\section{A Focus on Hard Tissue Therapies}

4.1. Bone Repair. In addition to the anti-inflammatory and anticancer properties outlined above, corals and their products have been shown to exert curative potential for metabolic 

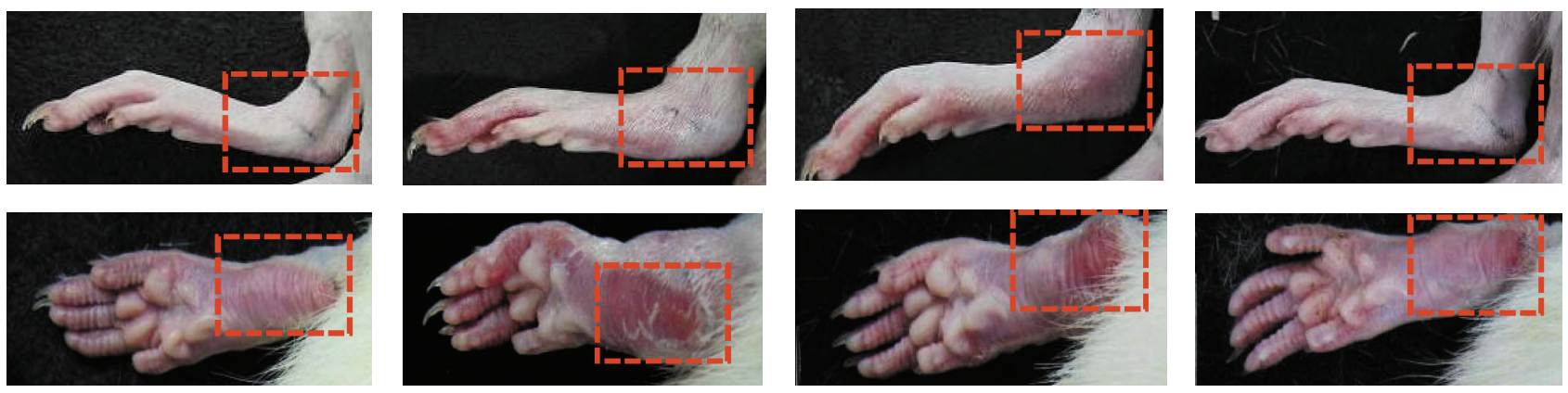

(c)

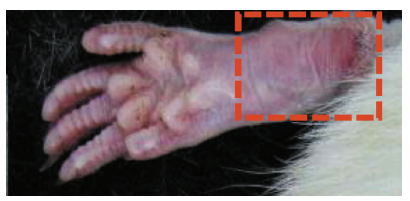

(b)

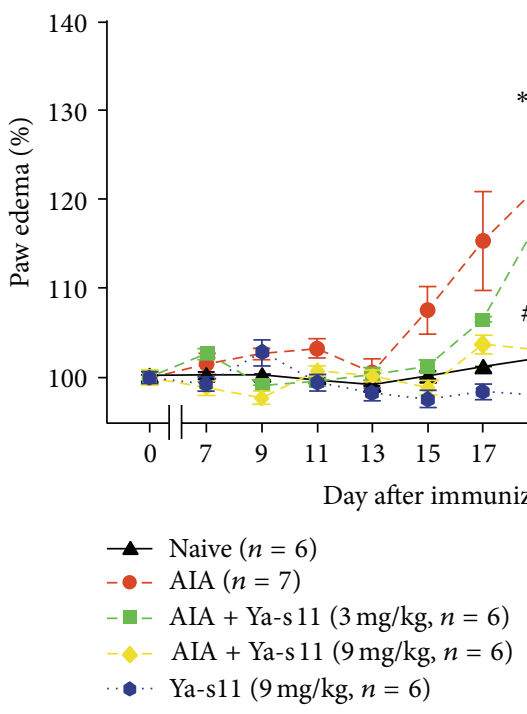

(e)

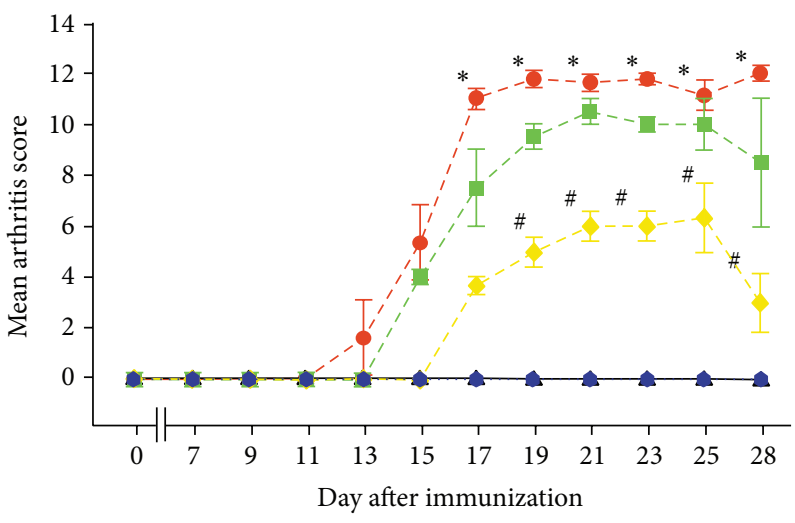

$$
\begin{aligned}
& - \text { Naive }(n=6) \\
& - \text { AIA }(n=7) \\
& \text { AIA + Ya-s } 11(3 \mathrm{mg} / \mathrm{kg}, n=6) \\
& \text { AIA + Ya-s } 11(9 \mathrm{mg} / \mathrm{kg}, n=6) \\
& \text { Ya-s11 }(9 \mathrm{mg} / \mathrm{kg}, n=6)
\end{aligned}
$$

(f)

FIGURE 4: Pictorial and graphical demonstrations of the attenuation of AIA symptoms in rats. From [18].

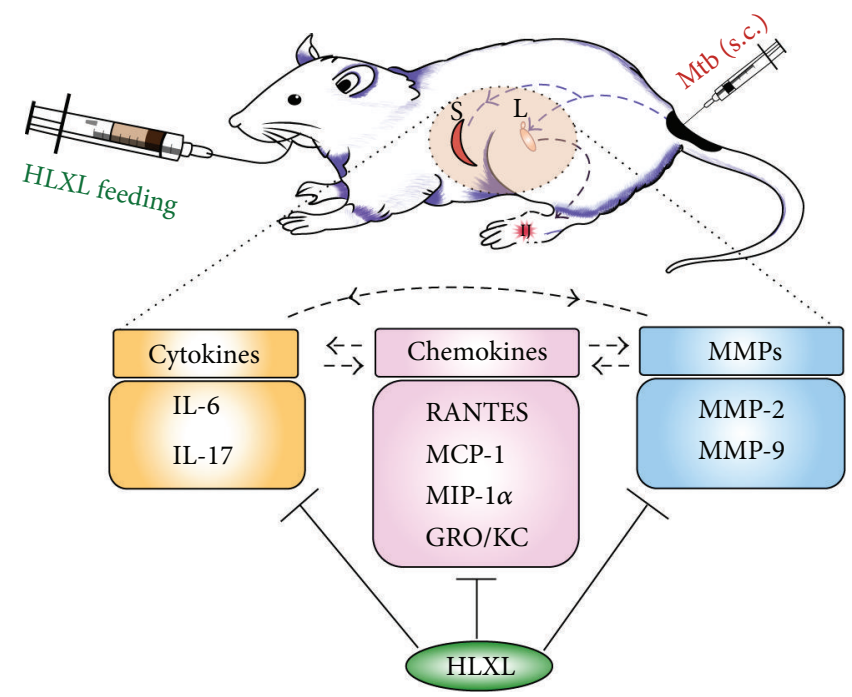

FIGURE 5: A schematic of how herbal supplements were administered and evaluated as a treatment for AIA in rats. From [19]. 


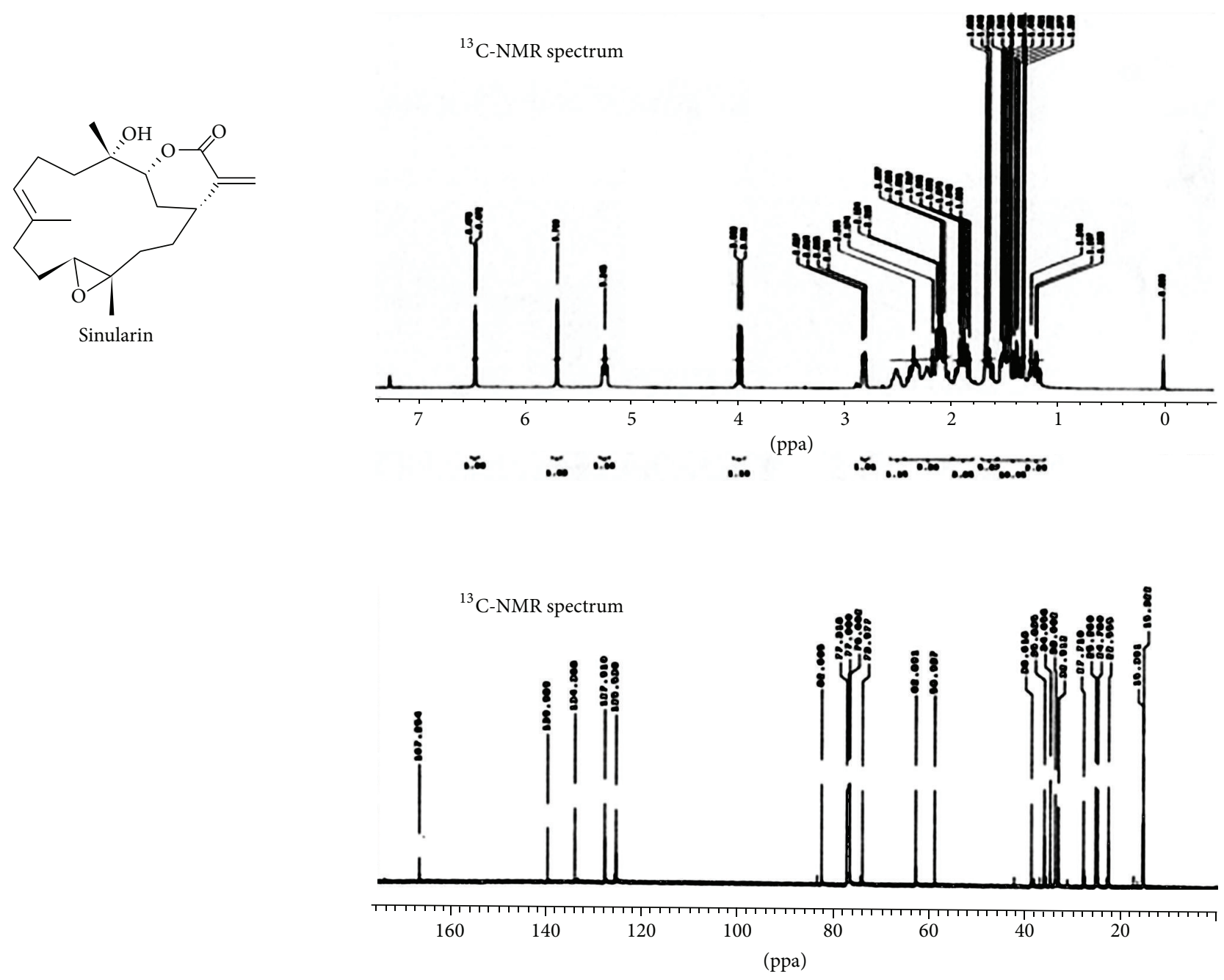

FIgURE 6: The chemical structure and ${ }^{13} \mathrm{C}-\mathrm{NMR}$ spectra of sinularin, a potential anticancer molecule isolated from Sinularia. From [20].

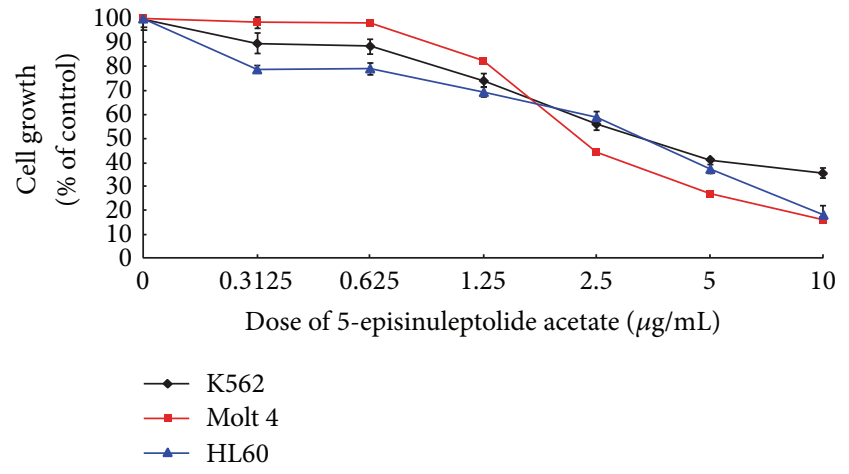

Figure 7: 5EPA activity against K562, Molt 4, and HL60 cell lines. From [24].

deficits as well. The naturally occurring calcium within the aragonite found in scleractinian hard corals, and the calcite found within the soft octocorals, when administered in conjunction with zeolite, a microporous mineral, assists in protecting against and reversing bone loss in mice that have been placed into an artificial, induced menopausal state [28] (mice, like most mammals, have an estrous cycle). This same effect was observed in rabbits when used with human plateletrich plasma [29]. Green et al. have highlighted the importance of the skeletal matrices of marine invertebrates for bone regeneration [30].

4.2. Restoration of Dental Deformities. Related to the potential for bone repair discussed above is bioprospecting being performed within corals as it pertains to dental treatment. Figueiredo et al. mention that their interest in this application has been increasing due to the low supply and difficulty of using human-derived substitutes for certain products used in dental procedures [31], making this a necessary and promising area of research regarding this untapped resource. They assert, however, that the coral skeleton in its unrefined form remains impractical because of its high degeneration (dissolution) rate. They argue that the potential 
benefit of coral skeleton may reside in refined coral that is modified (strengthened chemically) to increase its longevity and integrity. A particularly interesting experiment was performed which revealed that osteogenic bone marrow stromal cells used with coral scaffolds could be effective in repairing mandibular defects in canines [32].

\section{The Nervous System: Neuroprotective Compounds}

One of the highly prospective treatment modalities that can be added to the benefits of soft corals is the potential for abbreviating neurological deficits. Chen et al. extracted a neuroprotective compound, 11-dehydrosinularolide, from a coral that they believe could be used to treat Parkinson's disease [33]. Parkinson's disease is a highly debilitating neurodegenerative disorder that leads to severe impairment in the central nervous system and the necessity for special care. Most of the treatments that exist for Parkinson's disease only partially improve the symptoms and do not treat the source of the disease itself. Despite treatment using current pharmaceuticals, progression of the disease continues, with the patient losing motor skills and standard functions. Two mechanisms which impact the pathogenesis of Parkinson's disease, however, are inflammation and apoptosis [34]. Proinflammatory iNOS and COX-2 are two proteins that are well known to be associated with inflammation and are common indices and markers when testing for anti-inflammatory activity. Hoang et al. found that neuronal NOS and COX-2 caused DNA damage in a mouse model of Parkinson's disease [35]. The next logical step in trying to find a treatment for this debilitating disease is to find an agent that will prevent the inflammation induced by iNOS and COX-2. In Chen et al's experiment, investigators found that administration of 11-dehydrosinulariolide significantly reduced expression of iNOS and COX-2, with iNOS being almost entirely eliminated. It was also demonstrated to halt apoptosis, another factor thought to be associated with Parkinson's disease. This molecule provides highly promising potential for this severely incapacitating disease.

Not only have corals yielded molecules that confer neuroprotection, but also that reduce neuropathic pain. Austrasulfone, which is isolated from the soft coral Cladiella australis, demonstrated neuroprotective qualities via antiinflammatory pathways (reduction of iNOS and COX-2) [36]. It also showed potency in reducing neuropathic pain and slowing progression of atherosclerosis and multiple sclerosis models in rats. Another molecule that exerts antiinflammatory effects by reducing iNOS and COX-2 is capnellene, which is isolated from the soft coral, Capnella imbricata [37]. In conjunction with the anti-inflammatory properties, capnellene also exhibited antinociceptive properties. Nociception refers to the neurological pathway by which the body perceives pain caused by tissue-damaging stimuli. Therefore, this compound holds the potential not only to reduce inflammation causing or worsening neurodegenerative disorders, but also to reduce any pain that may be associated as a symptom.

\section{Hypertensive Treatments}

While most of the research done pertaining to corals and therapeutic applications has yielded results in cancer treatment and bone repair, other applications have also been identified. For example, coral sand, which is biogenic, is generated by the erosion of scleractinian corals. It has been used as a silicon source to reduce blood pressure as well as to improve the expression of genes that increase cardiovascular health in hypertensive rats [38].

\section{Comparing Corals with Therapeutic Properties of Other Invertebrates}

The reason that we and others are interested in corals as potential sources of medicinal molecules for humans is the vast amount of progress already made with other invertebrate organisms. Investigators have found an abundance of promising evidence for earthworms specifically as treatment modalities for inflammation, cancer, and coagulatory disorders [3943]. Earthworms have also been used historically as a source of nutrition $[44,45]$. Careful analyses do not seem to reveal that corals, as nutritious sources, afford this same sustenance as food. This is probably due to the small amount of tissue available in relation to their skeletal materials, even in soft corals. Current results clearly indicate certain medicinal qualities. Moreover, cytotoxicity has been demonstrated by molecules isolated from tunicates, another invertebrate [46]. With this large amount of evidence, it is definitely clear we should be looking towards other invertebrates in our bioprospecting endeavors.

\section{Conflict of Interests}

The authors declare that there is no conflict of interests regarding the publication of this paper.

\section{References}

[1] E. L. Cooper, "CAM, eCAM, bioprospecting: the 21st century pyramid," Evidence-Based Complementary and Alternative Medicine, vol. 2, no. 2, pp. 125-127, 2005.

[2] E. L. Cooper, “Bioprospecting: a CAM frontier," Evidence-Based Complementary and Alternative Medicine, vol. 2, no. 1, pp. 1-3, 2005.

[3] E. L. Cooper, "eCAM: an emerging linkage with ethnopharmacology?" Evidence-Based Complementary and Alternative Medicine, vol. 5, no. 4, pp. 365-366, 2008.

[4] E. L. Cooper, "Drug discovery, CAM and natural products," Evidence-Based Complementary and Alternative Medicine, vol. 1, pp. 215-217, 2004.

[5] A. W. Bruckner, "Life-saving products from coral reefs," Issues in Science and Technology, vol. 18, no. 3, p. 35, 2002.

[6] H. Schuhmacher and H. Zibrowius, "What is hermatypic?-a redefinition of ecological groups in corals and other organisms," Coral Reefs, vol. 4, no. 1, pp. 1-9, 1985.

[7] http://animals.nationalgeographic.com/animals/invertebrates/ coral/. 
[8] A. I. Tauber and L. Chernyak, Metchnikoff and the Origins of Immunology: From Metaphor to Theory, Oxford University Press, New York, NY, USA, 1991.

[9] E. L. Cooper, E. Kauschke, and A. Cossarizza, "Digging for innate immunity since Darwin and Metchnikoff," BioEssays, vol. 24, no. 4, pp. 319-333, 2002.

[10] E. L. Cooper, "Adaptive immunity from prokaryotes to eukaryotes: broader inclusions due to less exclusivity?" in Recent Advances in Immunology to Target Cancer, Inflammation and Infections, J. Kanwar, Ed., pp. 495-520, InTech, 2012.

[11] K. Kvell, E. Cooper, P. Engelmann, J. Bovari, and P. Nemeth, "Blurring borders: innate immunity with adaptive features," Clinical and Developmental Immunology, vol. 2007, Article ID 83671, 10 pages, 2007.

[12] C. V. Palmer and N. Traylor-Knowles, "Towards an integrated network of coral immune mechanisms," Proceedings of the Royal Society B, vol. 279, no. 1745, pp. 4106-4114, 2012.

[13] W. H. Hildemann, R. L. Raison, and G. Cheung, "Immunological specificity and memory in a scleractinian coral," Nature, vol. 270, no. 5634, pp. 219-223, 1977.

[14] W. H. Hildemann, P. L. Jokiel, C. H. Bigger, and I. S. Johnston, "Allogeneic polymorphism and alloimmune memory in the coral, Montipora verrucosa," Transplantation, vol. 30, no. 4, pp. 297-301, 1980.

[15] D. H. Marchbank, F. Berrue, and R. G. Kerr, "Eunicidiol, an antiinflammatory dilophol diterpene from Eunicea fusca," Journal of Natural Products, vol. 75, no. 7, pp. 1289-1293, 2012.

[16] E. Reina, C. Puentes, J. Rojas et al., "Fuscoside E: a strong anti-inflammatory diterpene from Caribbean octocoral Eunicea fusca," Bioorganic and Medicinal Chemistry Letters, vol. 21, no. 19, pp. 5888-5891, 2011.

[17] S. Y. Huang, N. F. Chen, W. F. Chen et al., "Sinularin from indigenous soft coral attenuates nociceptive responses and spinal neuroinflammation in carrageenan-induced inflammatory rat model," Marine Drugs, vol. 10, no. 12, pp. 1899-1919, 2012.

[18] Y. Y. Lin, Y. H. Jean, H. P. Lee et al., "A soft coral-derived compound, 11-epi-sinulariolide acetate suppresses inflammatory response and bone destruction in adjuvant-induced arthritis," PloS ONE, vol. 8, no. 5, Article ID e62926, 2013.

[19] H. Yu, D. Y. W. Lee, S. M. Nanjundaiah, S. H. Venkatesha, B. M. Berman, and K. D. Moudgil, "Microarray analysis reveals the molecular basis of antiarthritic activity of huo-luo-xiao-ling dan," Evidence-Based Complementary and Alternative Medicine, vol. 2013, Article ID 524746, 8 pages, 2013.

[20] R. Goto, K. Muramoto, M. Yamazaki, and H. Kamiya, "Purification and characterization of an agglutinin of the soft coral Sinularia species," Developmental and Comparative Immunology, vol. 16, no. 1, pp. 9-17, 1992.

[21] A. D. Wright, J. L. Nielson, D. M. Tapiolas, C. H. Liptrot, and C. A. Motti, "A great barrier reef Sinularia sp. yields two new cytotoxic diterpenes," Marine Drugs, vol. 10, no. 8, pp. 16191630, 2012.

[22] C.-H. Chao, K.-J. Chou, C.-Y. Huang et al., "Steroids from the soft coral Sinularia crassa," Marine Drugs, vol. 10, no. 2, pp. 439450, 2012.

[23] T.-R. Su, J.-J. Lin, C.-C. Chiu et al., "Proteomic investigation of anti-tumor activities exerted by sinularin against A2058 melanoma cells," Electrophoresis, vol. 33, no. 7, pp. 1139-1152, 2012.
[24] K. J. Huang, Y. C. Chen, M. El-Shazly, Y. C. Du, J. H. Su, and C. W. Tsao, "5-episinuleptolide acetate, a norcembranoidal diterpene from the formosan soft coral Sinularia sp., induces leukemia cell apoptosis through hsp90 inhibition," Molecules, vol. 18, no. 3, pp. 2924-2933, 2013.

[25] C.-C. Su, J.-H. Su, J.-J. Lin et al., "An investigation into the cytotoxic effects of 13-acetoxysarcocrassolide from the soft coral Sarcophyton crassocaule on bladder cancer cells," Marine Drugs, vol. 9, no. 12, pp. 2622-2642, 2011.

[26] S.-K. Wang and C.-Y. Duh, "New cytotoxic cembranolides from the soft coral Lobophytum michaelae," Marine Drugs, vol. 10, no. 2, pp. 306-318, 2012.

[27] S. K. Wang, S. Y. Puu, and C. Y. Duh, "New steroids from the soft coral nephthea chabrolii," Marine Drugs, vol. 11, no. 2, pp. 571-580, 2013.

[28] J. Banu, E. Varela, J. M. Guerra et al., "Dietary coral calcium and zeolite protects bone in a mouse model for postmenopausal bone loss," Nutrition Research, vol. 32, no. 12, pp. 965-975, 2012.

[29] A. M. Parizi, A. Oryan, Z. Shafiei-Sarvestani, and A. S. Bigham, "Human platelet rich plasma plus Persian Gulf coral effects on experimental bone healing in rabbit model: radiological, histological, macroscopical and biomechanical evaluation," Journal of Materials Science, vol. 23, no. 2, pp. 473-483, 2012.

[30] D. Green, M. Padula, J. Santos, J. Chou, B. Milthorpe, and B. Ben-Nissan, "A therapeutic potential for marine skeletal proteins in bone regeneration," Marine Drugs, vol. 11, no. 4, pp. 1203-1220, 2013.

[31] M. Figueiredo, J. Henriques, G. Martins, F. Guerra, F. Judas, and H. Figueiredo, "Physicochemical characterization of biomaterials commonly used in dentistry as bone substitutescomparison with human bone," Journal of Biomedical Materials Research B, vol. 92, no. 2, pp. 409-419, 2010.

[32] J. Yuan, W. J. Zhang, G. Liu et al., "Repair of canine mandibular bone defects with bone marrow stromal cells and coral," Tissue Engineering A, vol. 16, no. 4, pp. 1385-1394, 2010.

[33] W. F. Chen, C. Chakraborty, C. S. Sung et al., "Neuroprotection by marine-derived compound, 11-dehydrosinulariolide, in an in vitro Parkinson's model: a promising candidate for the treatment of Parkinson's disease," Naunyn-Schmiedeberg's Archives of Pharmacology, vol. 385, no. 3, pp. 265-275, 2011.

[34] N. Lev, E. Melamed, and D. Offen, “Apoptosis and Parkinson's disease," Progress in Neuro-Psychopharmacology and Biological Psychiatry, vol. 27, no. 2, pp. 245-250, 2003.

[35] T. Hoang, D.-K. Choi, M. Nagai et al., "Neuronal NOS and cyclooxygenase- 2 contribute to DNA damage in a mouse model of Parkinson disease," Free Radical Biology and Medicine, vol. 47, no. 7, pp. 1049-1056, 2009.

[36] Z.-H. Wen, C.-H. Chao, M.-H. Wu, and J.-H. Sheu, "A neuroprotective sulfone of marine origin and the in vivo antiinflammatory activity of an analogue," European Journal of Medicinal Chemistry, vol. 45, no. 12, pp. 5998-6004, 2010.

[37] Y.-H. Jean, W.-F. Chen, C.-S. Sung et al., "Capnellene, a natural marine compound derived from soft coral, attenuates chronic constriction injury-induced neuropathic pain in rats," British Journal of Pharmacology, vol. 158, no. 3, pp. 713-725, 2009.

[38] F. Maehira, K. Motomura, N. Ishimine, I. Miyagi, Y. Eguchi, and S. Teruya, "Soluble silica and coral sand suppress high blood pressure and improve the related aortic gene expressions in spontaneously hypertensive rats," Nutrition Research, vol. 31, no. 2, pp. 147-156, 2011.

[39] E. L. Cooper, M. Balamurugan, K. Parthasarathi, and L. S. Ranganathan, "Earthworm paste (Lampito mauritii, Kinberg) 
alters inflammatory, oxidative, haematological and serum biochemical indices of inflamed rat," European Review for Medical and Pharmacological Sciences, vol. 11, no. 2, pp. 77-90, 2007.

[40] E. L. Cooper and K. Hirabayashi, "Origin of innate immune responses: revelation of food and medicinal applications," Journal of Traditional and Complementary Medicine, vol. 3, article 204, no. 4, 2013.

[41] M. Balamurugan, K. Parthasarathi, E. L. Cooper, and L. S. Ranganathan, "Anti-inflammatory and anti-pyretic activities of earthworm extract-Lampito mauritii (Kinberg)," Journal of Ethnopharmacology, vol. 121, no. 2, pp. 330-332, 2009.

[42] E. L. Cooper and M. Balamurugan, "Unearthing a source of medicinal molecules," Drug Discovery Today, vol. 15, no. 21-22, pp. 966-972, 2010.

[43] E. L. Cooper, K. Hirabayashi, and M. Balamurugan, "Dilong: food for thought and medicine," Journal of Traditional and Complementary Medicine, vol. 2, article 242, no. 4, 2012.

[44] M. G. Paoletti, E. Buscardo, D. J. VanderJagt et al., "Nutrient content of earthworms consumed by Ye'Kuana Amerindians of the Alto Orinoco of Venezuela," Proceedings of the Royal Society B, vol. 270, no. 1512, pp. 249-257, 2003.

[45] M. G. Paoletti and D. Dufour, "Edible invertebrates among Amazonian Indians: a critical review of disappearing knowledge," in Ecological Implications of Mine Livestock, pp. 293-342, Science Publishers, Enfield, NH, USA, 2005.

[46] E. L. Cooper and D. Yao, "Diving for drugs: tunicate anticancer compounds," Drug Discovery Today, vol. 17, no. 11-12, pp. 636648, 2012.

[47] Y. F. Lin, C. Y. Kuo, Z. H. Wen et al., "Flexibilisquinone, a new anti-inflammatory quinone from the cultured soft coral sinularia flexibilis,” Molecules, vol. 18, no. 7, pp. 8160-8167, 2013.

[48] L. C. Hu, W. H. Yen, J. H. Su et al., "Cembrane derivatives from the soft corals, sinularia gaweli and sinularia flexibilis," Marine Drugs, vol. 11, no. 6, pp. 2154-2167, 2013.

[49] W. H. Yen, W. F. Chen, C. H. Cheng et al., "A new $5 \alpha, 8 \alpha-$ epidioxysterol from the soft coral Sinularia gaweli," Molecules, vol. 18, no. 3, pp. 2895-2903, 2013.

[50] C. H. Cheng, Y. S. Lin, Z. H. Wen, and J. H. Su, "A new cubitane diterpenoid from the soft coral Sinularia crassa," Molecules, vol. 17, no. 9, pp. 10072-10078, 2012.

[51] C. Y. Huang, J. H. Su, C. Y. Duh et al., "A new 9, 11-secosterol from the soft coral Sinularia granosa," Bioorganic \& Medicinal Chemistry Letters, vol. 22, no. 13, pp. 4373-4376, 2012.

[52] H. Y. Fang, C. H. Hsu, C. H. Chao et al., "Cytotoxic and antiinflammatory metabolites from the soft coral Scleronephthya gracillimum," Marine Drugs, vol. 11, no. 6, pp. 1853-1865, 2013.

[53] C. J. Tai, J. H. Su, C. Y. Huang et al., "Cytotoxic and antiinflammatory eunicellin-based diterpenoids from the soft coral cladiella krempfi," Marine Drugs, vol. 11, no. 3, pp. 788-799, 2013.

[54] C. H. Chao, Y. C. Wu, Z. H. Wen, and J. H. Sheu, "Steroidal carboxylic acids from soft coral paraminabea acronocephala," Marine Drugs, vol. 11, no. 1, pp. 136-145, 2013.

[55] H. P. Lee, S. Y. Huang, Y. Y. Lin et al., "Soft coral-derived lemnalol alleviates monosodium urate-induced gouty arthritis in rats by inhibiting leukocyte infiltration and iNOS, COX-2 and c-Fos protein expression," Marine Drugs, vol. 11, no. 1, pp. 99-113, 2013.

[56] C. H. Cheng, H. M. Chung, T. L. Hwang et al., "Echinoclerodane A: a new bioactive clerodane-type diterpenoid from a gorgonian coral Echinomuricea sp," Molecules, vol. 17, no. 8, pp. 94439450, 2012. 


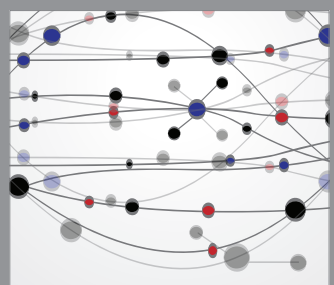

The Scientific World Journal
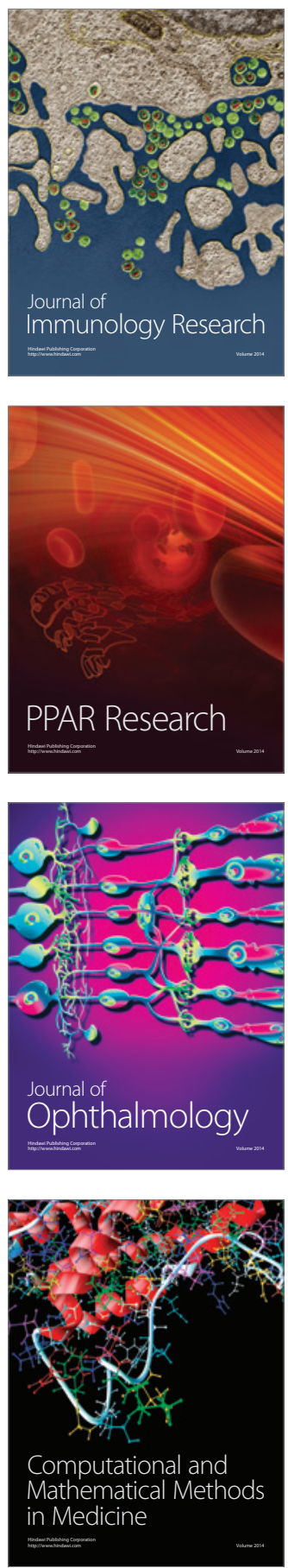

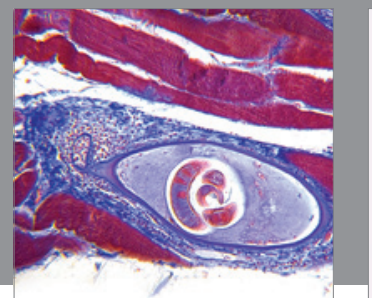

Gastroenterology

Research and Practice
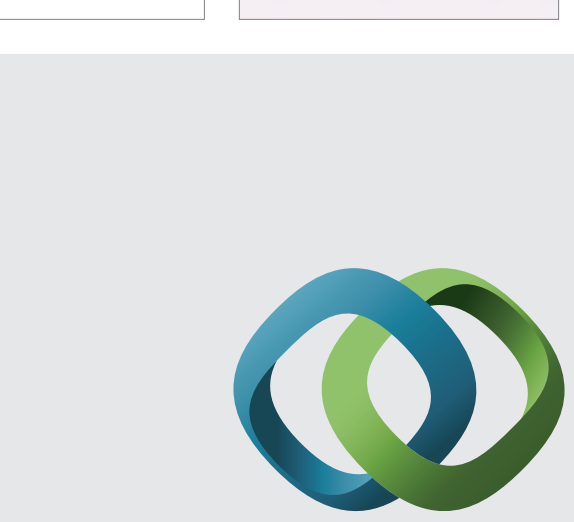

\section{Hindawi}

Submit your manuscripts at

http://www.hindawi.com
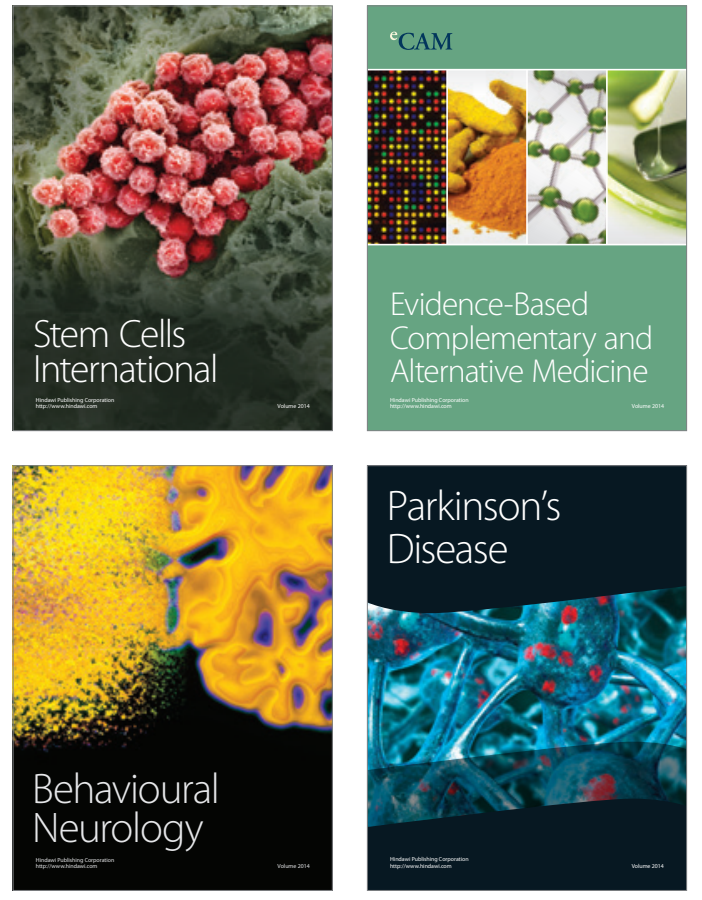
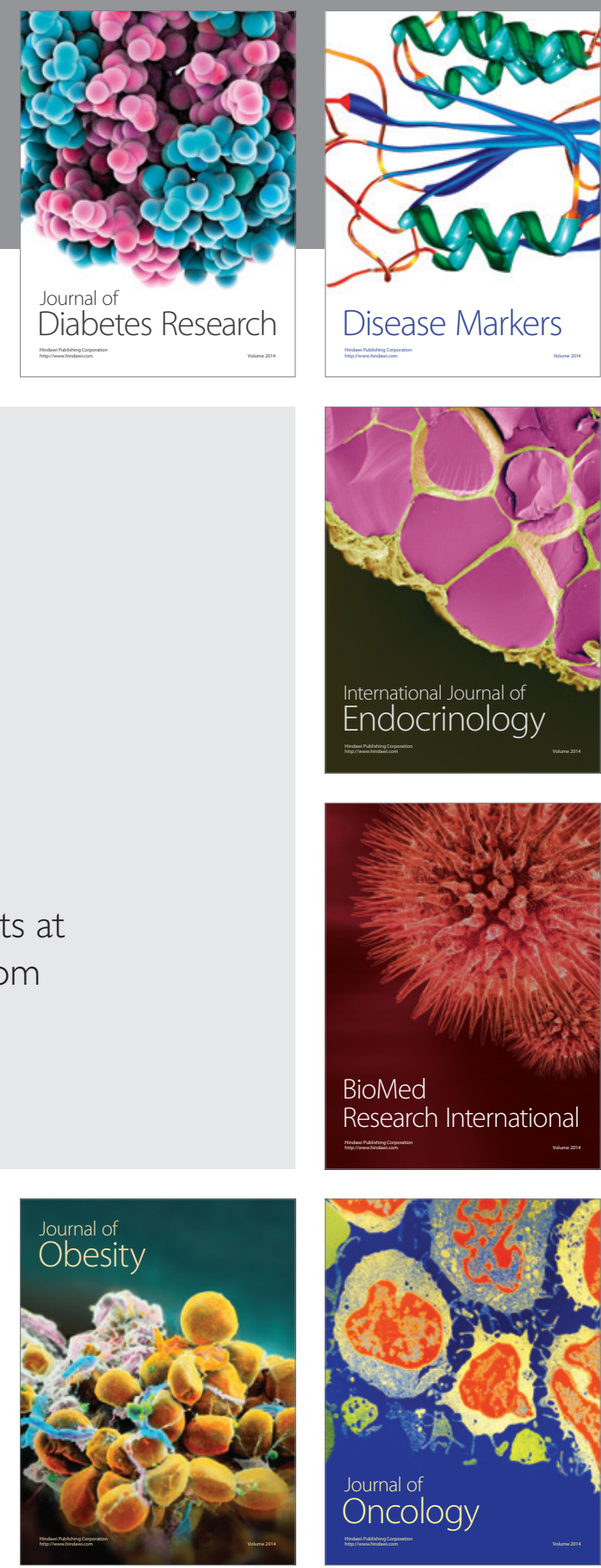

Disease Markers
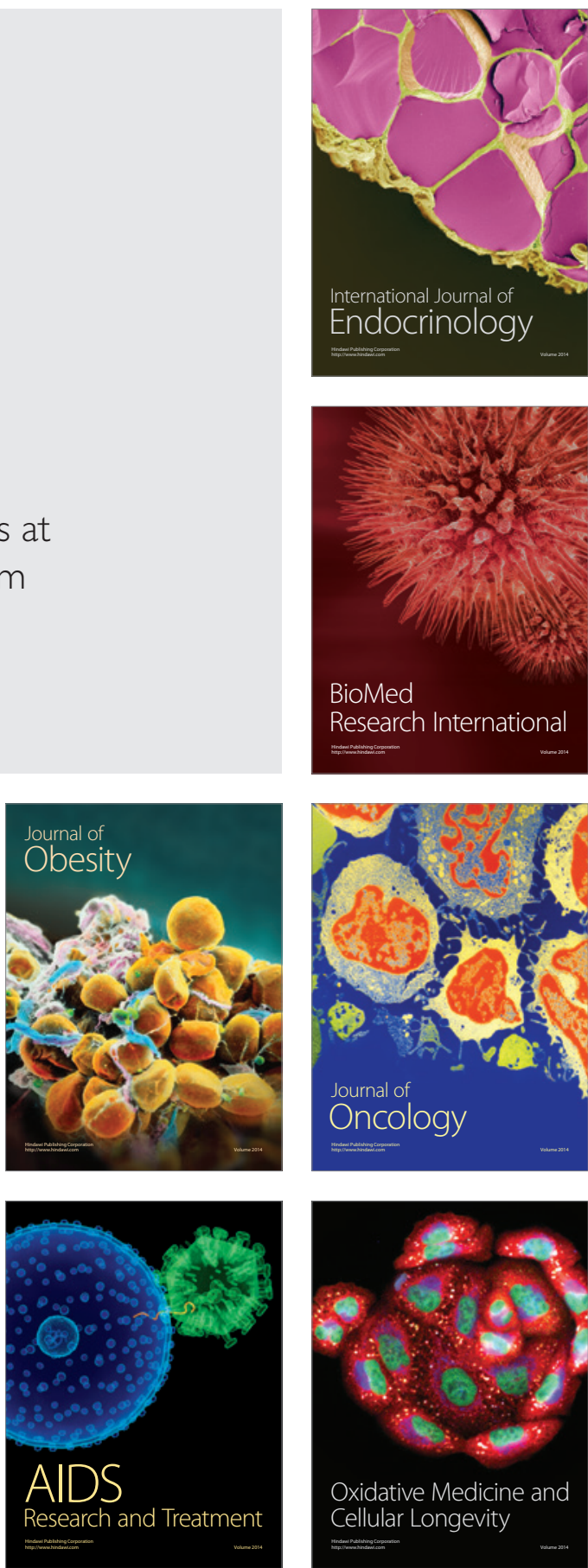